
\title{
ZS Research Square \\ Associations Between Paraben In Human Serum And Rheumatoid Arthritis Risks
}

\author{
Yun Zhao \\ Zhejiang University School of Medicine Second Affiliated Hospital \\ Jianli Qu \\ Zhejiang University of Technology \\ Meirong Zhao \\ Zhejiang University of Technology

\section{Pengfei Wu} \\ Hong Kong Baptist University \\ Jing Xue \\ Zhejiang University School of Medicine Second Affiliated Hospital \\ hangbiao jin ( $\sim$ hangbiao102@163.com ) \\ Zhejiang University of Technology https://orcid.org/0000-0002-7447-321X
}

\section{Research Article}

Keywords: MeP, PrP, Human serum, Rheumatoid arthritis, Immune markers.

Posted Date: March 3rd, 2022

DOI: https://doi.org/10.21203/rs.3.rs-1343384/v1

License: (c) (i) This work is licensed under a Creative Commons Attribution 4.0 International License. Read Full License 


\section{Abstract}

Parabens are widely used in consumer products resulting in frequent exposure to humans and some toxic effects in humans. However, little is known about the association between human paraben exposure and rheumatoid arthritis (RA). In this study, a case-control cohort $(n=290)$ were established in Hangzhou, China, aiming to quantify the residues of MeP, EtP, PrP, and BuP in serum samples and to determine their associations with RA risks. MeP (mean $4.7 \mathrm{ng} / \mathrm{mL},<\mathrm{LOD}-20 \mathrm{ng} / \mathrm{mL})$ was the predominant paraben in human serum, followed by $\operatorname{PrP}(1.9 \mathrm{ng} / \mathrm{mL},<\mathrm{LOD}-$ $24 \mathrm{ng} / \mathrm{mL}), \operatorname{EtP}(1.4 \mathrm{ng} / \mathrm{mL},<\mathrm{LOD}-10 \mathrm{ng} / \mathrm{mL})$, and BuP $(1.09 \mathrm{ng} / \mathrm{mL},<\mathrm{LOD}-10 \mathrm{ng} / \mathrm{mL})$. Human serum concentrations of MeP were correlated with the levels of rheumatoid factors [adjusted $\beta=0.19,95 \%$ confidence interval (Cl): $0.12,0.46]$, anti-cyclic citrullinated peptide antibody (adjusted $\beta=0.30,95 \% \mathrm{Cl}: 0.26,0.58$ ), immunoglobulin $\mathrm{G}$ (adjusted $\beta=0.24,95 \% \mathrm{Cl}$ : 0.21, 0.30). Significant associations between MeP (adjusted $\beta=0.15$, 95\% Cl: $0.037,0.28$ ) and PrP (adjusted $\beta=0.23,95 \% \mathrm{Cl}$ : 0.080, 0.38) exposure were correlated with C-reactive protein levels. In addtion, a correlation between MeP and odds ratios (OR) of $\mathrm{RA}_{(\mathrm{OR}}$ crude $=1.337, \mathrm{Cl}$ : 1.110, 1.624, $p=0.03$;

$\mathrm{OR}_{\text {adjusted }}=1.866, \mathrm{Cl}: 1.321,2.636, p=0.02$ ) was positive and significant. To our knowledge, this study first finds the significant associations among parabens exposure, change of specific immune marker, and RA risks, indicating that human exposure to parabens may increase the risk of RA.

\section{Introduction}

Parabens ( $p$-hydroxybenzoate) are a family of compounds with phenolic groups, mainly including methyl paraben (MeP), ethyl paraben (EtP), propyl paraben (PrP), and butyl paraben (BuP) (Fisher et al., 2020). Parabens have unique antibacterial properties with relatively low prices, hence they have been widely applied as antimicrobial preservatives and aromatics in various consumer products, such as food and beverages processing, personal care products, and drugs, for more than 90 years (Bledzka et al., 2014, Fisher et al., 2017, Snodin, 2017). Humans can be exposed to paraben in many ways, including cosmetics (Bledzka et al., 2014), diet (Zhao et al., 2021), indoor dust (Wang et al., 2012), and drinking water (Ferreira et al., 2011). The frequent detection of paraben in the blood (Li et al., 2020) and urine (Jurewicz et al., 2020) also verifies the high exposure of humans to this substance.

In 2008, Cosmetic Ingredient Review and US Food and Drug Administration conducted safety assessments on the use of parabens and concluded that their use in cosmetics was safe (Andersen, 2008, Fisher et al., 2017). However, parabens have long been considered as endocrine disruptors, and their estrogenic activities increased with the increase of the alkyl substituent length (Han and Washington, 2005). Moreover, parabens could cause a wide range of adverse health effects on animals and humans, such as significantly lower sperm counts and testosterone levels in rats (Kang et al., 2002, Oishi, 2001), decreased body weight and height in children (Wu et al., 2019), and decreased serum thyroid levels in humans (Aker et al., 2018). Hence, European Union imposed restrictions on the use of parabens in cosmetics from the year of 2009 (i.e., $<0.4 \%$ for single and $<0.8 \%$ for mixtures of parabens) (Zhu et al., 2020). China is the second-largest consumer of cosmetics in the world (Song et al., 2020), paraben exposure may pose a health risk to the Chinese population.

To date, there have been many studies on the association of paraben with immune diseases, most of which have focused on sensitive populations such as mothers and infants or children. For example, an epidemiologic study on 587 pregnant women in France suggested that exposure to EtP was correlated with the increased rate of asthma (Vernet et al., 2017). Only one study from the United States explored the relationships of paraben with adult autoimmune diseases, which reported that urinary MeP, PrP, EtP, and BuP levels were negatively associated with inflammatory bowel disease in people aged 20-80 years (de Silva et al., 2017). Therefore, studies between paraben 
and adult autoimmune diseases in China are still lacking. Rheumatoid arthritis (RA), a systemic heterogeneous autoimmune disease, is characterized by symptoms such as joint destruction (Yarwood et al., 2016, Zeng et al., 2017). Some studies claimed that 0.5 to $1.0 \%$ of adults worldwide are affected by this disease (Tian et al., 2021). Although information on demographic trends in the prevalence of RA is scant, concern exists that there may be an increased risk of developing RA due to the increasingly frequent exposure to organic pollutants in the environment. The underlying pathogenic mechanism of RA is considered to be a disturbed immune response inducing increased susceptibility in the host in response to single or multiple environmental risk factors. Rheumatoid factors (RF), anticyclic citrullinated peptide antibody (ACPA), C-reactive protein (C-RP), and erythrocyte sedimentation rate (ESR) are commonly used as diagnostic markers of RA. Watkins et al. (2015) explored the relationship between paraben exposure and markers of oxidative stress and inflammation and reported that BuP concentrations were associated with C-RP levels. Therefore, it is necessary to quantify the parabens residuals in serum and to determine the relationship between RA and parabens exposure in humans.

Serum is one of the major matrix used for human biological monitoring studies (Angerer et al., 2007). Indicator values related to RA, including ACPA, RF, C-RP, ESR, and immunoglobulin G (IgG), are also determined in the human serum. Although parabens in the human body have a short half-life of about 24 to 72 hours, parabens can still be detected in human serum and blood samples (Boberg et al., 2010, Janjua et al., 2008). A domestic biomonitoring study has suggested that the detected frequencies of MeP, EtP, PrP, and BuP in young adult blood were $82 \%, 57 \%$, $77 \%$, and $41 \%$, respectively (Zhang et al., 2020). Moreover, paraben exposure is widespread in different populations from various countries (Adoamnei et al., 2018, Iribarne-Duran et al., 2020, Vela-Soria et al., 2013).

In the present work, we established a case-control cohort, including 152 RA cases and 138 controls, and collected their whole blood samples in Hangzhou, China. Four parabens, including MeP, EtP, PrP, and BuP, were quantified in these serum samples. The main purposes of this study were to determine the profile of target parabens in human serum and to explore the relationship among paraben levels in human serum, immune markers, and incidence of RA by adjusting the covariates. This study contributes to our better understanding of the risk of human immunotoxicity from exposure to parabens.

\section{Methods And Materials}

Study Population and Sample Collection. Between August 2018 and November 2020, a case-control cohort, including 152 RA cases and 138 non-RA people (controls), was established in Hangzhou, China. After signing a written informed consent, all participants were received questionnaires regarding their demographic and health-related characteristics. The minimum eligibility criteria for RA patients included long-term residence in Hangzhou, with no occupational exposure, without the experience of infection in the last two months, and without pregnant or breastfeeding women. Recruitment criteria for controls were comparable to those described above, with the addition of no self-reported history of cancer and tumors. We extracted data on immune markers of subjects from medical records, including ACPA, RF, C-RP, ESR, and three types of immunoglobulins (IgA, IgG, and IgM). The study protocol was authorized by the Ethics Committee of the Second Affiliated Hospital of Zhejiang University School of Medicine.

With the help of nurses in the hospital, the blood samples were collected from the study population in BD-Vacutainer collection tubes (Becton, Dickinson and Company, NJ, USA). After that, all blood samples were centrifuged at 4500

$\mathrm{r} / \mathrm{min}$ for $15 \mathrm{~min}$. The serums were transferred to new PP vials and stored in freezers at $-80^{\circ} \mathrm{C}$ until extraction. During the sampling campaign, field blanks ( $5 \mathrm{~mL}$ of Milli-Q water) were transported along with the real human serum samples. 
Sample Extraction. Serum paraben concentrations were analyzed using the method of Li et al. (2020), with slight modification. In brief, $500 \mu \mathrm{L}$ of serum spiked with $10 \mathrm{ng}$ internal standards was added into $15 \mathrm{~mL}$ polypropylene (PP) tubes. Then, $6 \mathrm{~mL}$ of acetonitrile containing $1 \%$ formic acid was added to serum samples. The mixture was treated by sonication $(53 \mathrm{kHz}$ ) for $30 \mathrm{~min}$ and centrifuged at $5000 \mathrm{r} / \mathrm{min}$ for $10 \mathrm{~min}$. The supernatant was transferred to a new $15 \mathrm{~mL}$ PP tube, and the above extraction process was repeated one more time. The supernatants were combined and evaporated to $3 \mathrm{~mL}$ with mild nitrogen. The concentrated mixture was further processed by Oasis MCX SPE cartridge (100 mg/3 mL; Waters, USA). Before loading, the cartridge was pretreated with $5 \mathrm{~mL}$ of methanol and $5 \mathrm{~mL}$ of Milli-Q water. Target analytes eluted with $5 \mathrm{~mL}$ of methanol were evaporated to dryness with nitrogen and reconstituted with $100 \mu \mathrm{L}$ of methanol for instrumental analysis.

Instrumental Analysis. Analysis of parabens was conducted by high-performance liquid chromatography (HPLC) equipped with a triple quadrupole mass spectrometer (MS/MS), using an ACQUITY UPLC BEH $\mathrm{C}_{18}$ column (1.7 $\mu \mathrm{m}$, $2.1 \mathrm{~mm} \times 50 \mathrm{~mm}$; Waters, Milford, USA) maintained at $40^{\circ} \mathrm{C}$. The mobile phase was pure water containing $2 \mathrm{mM}$ ammonium acetate $(A)$ and methanol $(B)$, with a flow rate of $0.3 \mathrm{~mL} / \mathrm{min}$. The elution gradient started at $75 \% A$ and $25 \% \mathrm{~B}$, then ramped up to $45 \%$ B by $1.5 \mathrm{~min}$, increased to $100 \% \mathrm{~B}$ at $8 \mathrm{~min}$, held for $1 \mathrm{~min}$, and returned to the initial condition within $0.5 \mathrm{~min}$. The MS/MS was operated in negative ionization mode and a chromatogram was recorded using multiple reaction monitoring (MRM). The ionization source temperature was $450{ }^{\circ} \mathrm{C}$. Parent and product ions of four parabens are listed in the Supporting Information (SI, Table S1).

Quality Assurance and Quality Control. In this study, all solvents and reagents used were examined for paraben contamination, and no detectable parabens were observed. Field blank sample analysis was performed before the detection of real samples, and no measurable parabens were detected. After every ten samples, $10 \mu \mathrm{L}$ of methanol was analyzed to monitor the background contamination. At the same time as extracting real samples, procedural blank samples were also extracted. No detectable MeP, EtP, PrP, and BuP were detected in procedural blanks, so LODs of all target parabens were set as the concentrations corresponding to the three-times of signal-to-noise ratio. LODs of MeP, EtP, PrP, and BuP were 0.05, 0.09, 0.12, and $0.10 \mathrm{ng} / \mathrm{mL}$, respectively (SI, Table S2). The internal-standard method was used for the quantification of parabens in human serum. Calibration curves of parabens (at least five concentration points) were highly linear with correlation coefficients higher than 0.995 . Extraction recoveries of all compounds were determined by analyzing real human serum samples $(n=3)$ in this study and commercial fetal bovine serum ( $n=3$ ) spiked with the mixture of native standards (each spiked at $10 \mathrm{ng} / \mathrm{mL}$ ). The mean extraction recoveries of parabens in human serum ranged from $97-123 \%$. The intra-day relative standard deviation (RSD) of human serum samples $(n=5)$ spiked at $10 \mathrm{ng} / \mathrm{mL}$ parabens ranged from 8.6-12.8\% and inter-day RSD $(n=5)$ within 3 weeks was $12-29 \%$.

Statistical Analysis. We performed preliminary descriptive statistics to assess the demographic characteristics, immune markers, and serum paraben concentrations. Associations between individual serum paraben concentrations and serum immune marker levels were evaluated using Spearman's rank correlation analysis $\left(r_{s}\right)$. We used LOD $/ \sqrt{ } 2$ to calculate the concentrations of samples below the LOD. The In-transformed paraben concentrations were deemed as independent variables in the regression model. To satisfy the normal distribution of the residuals, all serum immune marker levels were In-transformed. The multiple linear regression analysis was used to evaluate relationships of paraben concentrations in serum with immune marker levels. The stepwise selection method was adopted in this model to find the most suitable final model. Besides, non-linear trends were explored by dividing the natural In-transformed paraben concentrations into quartiles, with the lowest quartile as the reference group. The logistic regression was conducted to further determine the association of paraben exposure with the incidence of RA. The models were adjusted for sex (male and female; categorical), age at enrollment $(<40,40-50,51-60,61-70,>$ 
70; categorical), education level (>12, 9-12<9; categorical), BMI (<18.5, 18.5-24.9, > 24.9; categorical), annual household income (<50000,50000-100000, > 100000; categorical), and parity $(0,1,2, \geq 3$; categorical). All statistical analysis was performed using IBM SPSS Statistics (version 25; Chicago, IL, USA). The statistical significance was set as $p<0.05$.

\section{Results}

Demographic Characteristics. Table 1 provides immune markers (mean \pm SD) and descriptive data $[n(\%)]$ of all participants $(n=290)$. The study population ranged in the age from $<40$ to $>70$, which is divided into 5 grades. The mean (range) age of the study population was 55 (28-84) years. More than half of the study population had BMI between 18.5 and 24.9 and had been educated for more than 9 years. $72 \%$ of RA cases never smoke, which is comparable to the controls (70\%). Overall. there was no obvious difference in the characteristics of the RA cases and controls. 
Table 1

Demographic Characteristics in This Study [ $n=290 ; \mathrm{n}(\%)$ or mean \pm SD]

\begin{tabular}{|c|c|c|}
\hline Characteristic & Controls $(n=138)$ & RA cases $(n=152)$ \\
\hline \multicolumn{3}{|l|}{ Age (years) } \\
\hline$<40$ & $20(14)$ & $21(14)$ \\
\hline $40-50$ & $48(34)$ & $37(25)$ \\
\hline $51-60$ & $38(27)$ & $35(24)$ \\
\hline $61-70$ & $22(16)$ & $30(20)$ \\
\hline$>70$ & $13(9)$ & $26(17)$ \\
\hline \multicolumn{3}{|l|}{ Education level (years) } \\
\hline$>12$ & $34(24)$ & $37(25)$ \\
\hline $9-12$ & $76(54)$ & $75(51)$ \\
\hline$<9$ & $32(22)$ & $36(24)$ \\
\hline \multicolumn{3}{|c|}{ Body mass index $\left(B M l, k g / m^{3}\right)$} \\
\hline Underweight $<18.5$ & $30(22)$ & $26(17)$ \\
\hline Normal 18.5 to $<24.9$ & $98(73)$ & $110(70)$ \\
\hline Overweight $>24.9$ & $6(5)$ & $20(13)$ \\
\hline \multicolumn{3}{|c|}{ Annual household income (RMB/year) } \\
\hline$<50000$ & $46(32)$ & $52(36)$ \\
\hline $50000-100000$ & $66(45)$ & $62(43)$ \\
\hline$>100000$ & $33(23)$ & $31(21)$ \\
\hline \multicolumn{3}{|l|}{ Medical history } \\
\hline Yes & $35(25)$ & $24(16)$ \\
\hline No & $103(75)$ & $128(84)$ \\
\hline \multicolumn{3}{|l|}{ Smoking habit } \\
\hline Never & $99(72)$ & $107(70)$ \\
\hline Current & $20(14)$ & $21(14)$ \\
\hline Ever & $19(14)$ & $24(16)$ \\
\hline \multicolumn{3}{|l|}{ Parity } \\
\hline 0 & $4(3)$ & $8(5)$ \\
\hline 1 & $50(34)$ & $48(32)$ \\
\hline 2 & $61(41)$ & $58(38)$ \\
\hline
\end{tabular}




\begin{tabular}{|lll|}
\hline Characteristic & Controls $(\boldsymbol{n = 1 3 8})$ & RA cases $(\boldsymbol{n}=\mathbf{1 5 2})$ \\
\hline$\geq 3$ & $33(22)$ & $38(25)$ \\
\hline Sex & & $71(52)$ \\
\hline Male & $70(46)$ & $66(48)$ \\
\hline Female & $83(54)$ & \\
\hline Immune markers & & $50 \pm 33$ \\
\hline ESR (mm/h) & $15 \pm 8.0$ & $31 \pm 27$ \\
\hline C-RP (mg/L) & $2.2 \pm 1.0$ & $316 \pm 286$ \\
\hline RF (IU/mL) & $9.8 \pm 33$ & $449 \pm 304$ \\
\hline ACPA (IU/mL) & $11 \pm 1.8$ & $3.3 \pm 2.4$ \\
\hline IgA (g/L) & $2.1 \pm 0.6$ & $25 \pm 5.3$ \\
\hline IgG (g/L) & $12 \pm 2.2$ & $1.4 \pm 1.5$ \\
\hline IgM (g/L) & $1.0 \pm 0.5$ & \\
\hline
\end{tabular}

Human Serum Concentrations of Parabens. Table 2 displays the concentrations of parabens in human serum samples. Among 4 parabens, MeP had the highest detection frequency (100\% and $97 \%$, respectively) in both RA cases and controls, followed by EtP (63\% and 50\%), and $\operatorname{PrP}(71 \%$ and $53 \%)$. BuP was detected in $55 \%$ and $43 \%$ of RA cases and controls serum samples, respectively. The mean serum concentrations of parabens ranked in the order of $\operatorname{MeP}(5.8 \mathrm{ng} / \mathrm{mL})>\operatorname{PrP}(2.0 \mathrm{ng} / \mathrm{mL})>\operatorname{EtP}(1.6 \mathrm{ng} / \mathrm{mL})>\operatorname{BuP}(1.4 \mathrm{ng} / \mathrm{mL})$, accounting for $52.7 \%, 18.8 \%, 14.9 \%$, and $13.6 \%$ of the total paraben burden in RA human samples, respectively (Fig. 1). Serum concentrations of MeP in RA cases (mean $\pm \mathrm{SD}, 5.8 \pm 4.6 \mathrm{ng} / \mathrm{mL})$ were significantly $(p<0.05)$ higher than that in controls $(4.0 \pm 4.2 \mathrm{ng} / \mathrm{mL})$. 
Table 2

Distribution of Parabens Concentrations $(\mathrm{ng} / \mathrm{mL})$ in Human Serum from RA cases $(n=152)$ and controls $(n=138)$. The DR mean detection rate $(\%)$.

\begin{tabular}{|llllllll|}
\hline Analyte & DR (\%) & Min & Mean \pm SD & Max & \multicolumn{3}{l}{ Quartile } \\
\cline { 6 - 8 } & & & & & 25th & 50th & 75th \\
\hline RA Cases $(n=152)$ & & & & & & \\
\hline MeP & 100 & 0.10 & $5.8 \pm 4.6$ & 20 & 2.0 & 4.7 & 8.1 \\
\hline EtP & 63 & $<$ LOD & $1.6 \pm 1.8$ & 10 & $<$ LOD & 0.96 & 2.2 \\
\hline PrP & 71 & $<$ LOD & $2.0 \pm 3.8$ & 24 & $<$ LOD & 0.74 & 2.1 \\
\hline BuP & 55 & $<$ LOD & $1.4 \pm 1.5$ & 10 & $<$ LOD & 0.98 & 1.7 \\
\hline Controls $(n=138)$ & & & & & & \\
\hline MeP & 97 & $<$ LOD & $4.0 \pm 4.2$ & 18 & 1.2 & 2.6 & 5.4 \\
\hline EtP & 50 & $<$ LOD & $1.0 \pm 1.7$ & 8.3 & $<$ LOD & 0.33 & 1.0 \\
\hline PrP & 53 & $<$ LOD & $1.6 \pm 3.4$ & 18 & $<$ LOD & 0.49 & 1.4 \\
\hline BuP & 43 & $<$ LOD & $0.66 \pm 0.53$ & 3.2 & $<$ LOD & $<$ LOD & 0.77 \\
\hline
\end{tabular}

Associations Between Serum Parabens and Immune Markers. Associations between concentrations of individual parabens in human serum, as well as between paraben concentrations and immune markers levels in human serum are displayed in the Table S3. Spearman correlation analysis showed that levels of MeP in human serum were significantly correlated with RF $\left(r_{s}=0.48, p<0.05\right), \operatorname{ACPA}\left(r_{s}=0.56, p<0.01\right), \mathrm{C}-\mathrm{RP}\left(r_{s}=0.35, p<0.05\right)$, as well as IgG $\left(r_{s}=0.43, p<0.05\right)$ levels, but were not correlated with $\mathrm{ESR}\left(r_{s}=0.14, p=0.43\right), \operatorname{lgA}\left(r_{s}=0.089, p=0.58\right)$, and $\operatorname{lgM}\left(r_{s}=\right.$ $0.14, p=0.45)$. PrP concentrations in human serum samples were significantly $\left(r_{s}=0.40, p<0.05\right)$ correlated with CRP levels.

For all participants, one unit increase in serum natural log-transformed MeP concentrations was correlated with increased in natural log-transformed RF levels [crude $\beta=0.16,95 \%$ confidence interval (Cl): 0.094, 0.33, $p<0.05$; adjusted $\beta=0.19,95 \%$ confidence interval $(\mathrm{Cl}): 0.12,0.46, p<0.05]$ (Table 3 ) in both crude and adjusted models. The coefficients of log-transformed MeP to the dependent variable ACPA (crude $\beta=0.28, \mathrm{Cl}: 0.11-0.44, p<0.05$; adjusted $\beta=0.30$, Cl: $0.26-0.58, p<0.05$ ), C-RP (crude $\beta=0.22, \mathrm{Cl}: 0.070-0.37, p<0.05$; adjusted $\beta=0.23, \mathrm{Cl}: 0.08-0.38, p<$ 0.05), and IgG (crude $\beta=0.23, \mathrm{Cl}: 0.20-0.26, p<0.05$; adjusted $\beta=0.24, \mathrm{Cl}: 0.21-0.30, p<0.05$ ) were positively and statistically significant. Besides, the parabens concentrations (In-transformed) were divided into quartiles to explore the nonlinear trends with immune markers of RA (Table S4). 
Table 3

Multivariable Linear Regression Coefficients $\beta$ (95\% Confidence Interval) for Immune Markers and Ln-Transformed Paraben Concentrations in Study Population.

\begin{tabular}{|c|c|c|c|c|c|c|c|c|}
\hline \multirow[t]{2}{*}{ Outcome } & \multicolumn{2}{|l|}{ MeP } & \multicolumn{2}{|l|}{ EtP } & \multicolumn{2}{|l|}{ PrP } & \multicolumn{2}{|l|}{ BuP } \\
\hline & crude $\beta$ & $\underset{\beta}{\text { adjusted }}$ & crude $\beta$ & $\underset{\beta}{\text { adjusted }}$ & crude $\beta$ & $\underset{\beta}{\text { adjusted }}$ & crude $\beta$ & $\underset{\beta}{\text { adjusted }}$ \\
\hline RF & $\begin{array}{l}0.16 \\
(0.094, \\
0.33)\end{array}$ & $\begin{array}{l}0.19 \\
(0.12, \\
0.46)\end{array}$ & $\begin{array}{l}0.011 \\
(-0.19 \\
0.21)\end{array}$ & $\begin{array}{l}0.011 \\
(-0.14 \\
0.16)\end{array}$ & $\begin{array}{l}0.17 \\
(-0.032, \\
0.39)\end{array}$ & $\begin{array}{l}0.18 \\
(-0.038 \\
0.39)\end{array}$ & $\begin{array}{l}0.32 \\
(-0.067 \\
0.72)\end{array}$ & $\begin{array}{l}0.33 \\
(0.055 \\
0.60)\end{array}$ \\
\hline ACPA & $\begin{array}{l}0.28 \\
(0.11 \\
0.44)\end{array}$ & $\begin{array}{l}0.30 \\
(0.26 \\
0.58)\end{array}$ & $\begin{array}{l}0.18 \\
(-0.028, \\
0.39)\end{array}$ & $\begin{array}{l}0.12 \\
(-1.3 \\
1.5)\end{array}$ & $\begin{array}{l}0.24 \\
(0.050 \\
0.44)\end{array}$ & $\begin{array}{l}0.14 \\
(-1.3 \\
1.1)\end{array}$ & $\begin{array}{l}0.40 \\
(0.040 \\
0.58)\end{array}$ & $\begin{array}{l}0.35 \\
(-0.95 \\
1.4)\end{array}$ \\
\hline C-RP & $\begin{array}{l}0.13 \\
(0.015 \\
0.25)\end{array}$ & $\begin{array}{l}0.15 \\
(0.037 \\
0.283)\end{array}$ & $\begin{array}{l}0.23 \\
(0.087 \\
0.38)\end{array}$ & $\begin{array}{l}0.22 \\
(-0.20 \\
0.64)\end{array}$ & $\begin{array}{l}0.22 \\
(0.070, \\
0.37)\end{array}$ & $\begin{array}{l}0.23 \\
(0.08, \\
0.38)\end{array}$ & $\begin{array}{l}0.36 \\
(0.084, \\
0.63)\end{array}$ & $\begin{array}{l}0.36 \\
(-0.30 \\
1.0)\end{array}$ \\
\hline ESR & $\begin{array}{l}0.19 \\
(0.11 \\
0.27)\end{array}$ & $\begin{array}{l}0.18 \\
(0.051 \\
0.31)\end{array}$ & $\begin{array}{l}0.10 \\
(0.007 \\
0.19)\end{array}$ & $\begin{array}{l}0.10 \\
(-0.053 \\
0.26)\end{array}$ & $\begin{array}{l}0.042 \\
(-0.059 \\
0.14)\end{array}$ & $\begin{array}{l}0.042 \\
(-0.12 \\
0.29)\end{array}$ & $\begin{array}{l}0.22 \\
(0.039 \\
0.41)\end{array}$ & $\begin{array}{l}0.24 \\
(-0.078 \\
0.55)\end{array}$ \\
\hline $\lg A$ & $\begin{array}{l}0.12 \\
(0.073, \\
0.18)\end{array}$ & $\begin{array}{l}0.13 \\
(-0.062 \\
0.32)\end{array}$ & $\begin{array}{l}0.047 \\
(-0.023 \\
0.11)\end{array}$ & $\begin{array}{l}0.049 \\
(-0.19 \\
0.29)\end{array}$ & $\begin{array}{l}0.057 \\
(-0.025 \\
0.13)\end{array}$ & $\begin{array}{l}0.058 \\
(-0.22 \\
0.34)\end{array}$ & $\begin{array}{l}0.16 \\
(0.045 \\
0.29)\end{array}$ & $\begin{array}{l}0.17 \\
(-0.25 \\
0.59)\end{array}$ \\
\hline IgG & $\begin{array}{l}0.23 \\
(0.20 \\
0.26)\end{array}$ & $\begin{array}{l}0.24 \\
(0.21 \\
0.30)\end{array}$ & $\begin{array}{l}0.093 \\
(0.012, \\
0.083)\end{array}$ & $\begin{array}{l}0.093 \\
(-0.22 \\
0.41)\end{array}$ & $\begin{array}{l}0.069 \\
(0.023 \\
0.11)\end{array}$ & $\begin{array}{l}0.074 \\
(-0.33 \\
0.47)\end{array}$ & $\begin{array}{l}0.036 \\
(-0.030 \\
0.10)\end{array}$ & $\begin{array}{l}-0.033 \\
(-0.56, \\
0.49)\end{array}$ \\
\hline $\lg M$ & $\begin{array}{l}0.038 \\
(-0.028 \\
0.10)\end{array}$ & $\begin{array}{l}0.046 \\
(-0.054 \\
0.14)\end{array}$ & $\begin{array}{l}0.051 \\
(-0.043, \\
0.14)\end{array}$ & $\begin{array}{l}0.061 \\
(-0.057 \\
0.18)\end{array}$ & $\begin{array}{l}-0.064 \\
(-0.16 \\
0.032)\end{array}$ & $\begin{array}{l}-0.035 \\
(-0.16 \\
0.095)\end{array}$ & $\begin{array}{l}-0.10 \\
(-0.23 \\
0.026)\end{array}$ & $\begin{array}{l}-0.016 \\
(-0.21 \\
0.18)\end{array}$ \\
\hline
\end{tabular}

Significant associations of serum paraben concentration with an incidence of RA were found here (Table 4). The crude and adjusted odds ratio (OR) for RA was 1.337 and 1.866, respectively, for a unit increase in natural log-

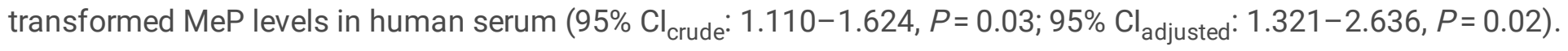
Apart from the above findings, we did not find a statistically significant association between other individual parabens and the incidence of RA. 
Table 4

Crude and adjusted odds ratio (OR, 95\% confidence intervals $(\mathrm{CI})$ ) for In-transformed parabens exposure and risk of rheumatoid arthritis using a logistic regression model.

\begin{tabular}{|c|c|c|c|c|}
\hline \multirow[t]{2}{*}{ Analyte } & \multicolumn{2}{|l|}{ Crude } & \multicolumn{2}{|l|}{ Adjusted } \\
\hline & OR (95\% Cl) & $P_{\text {trend }}$ & OR (95\% Cl) & $P_{\text {trend }}$ \\
\hline MeP & $1.337(1.110,1.624)$ & 0.03 & $1.866(1.321,2.636)$ & 0.02 \\
\hline EtP & $1.255(0.998,1.562)$ & 0.07 & $1.657(0.976,2.062)$ & 0.1 \\
\hline PrP & $1.466(1.129,1.905)$ & 0.06 & $1.208(0.564,1.823)$ & 0.07 \\
\hline BuP & $0.918(0.507,1.452)$ & 0.8 & $0.929(0.518,1.423)$ & 0.9 \\
\hline
\end{tabular}

\section{Discussion}

MeP (mean, $4.7 \mathrm{ng} / \mathrm{mL}$ ) is the predominant paraben in human serum from all participants, with a detection frequency of $98 \%$, which is consistent with the study on pregnant Chinese women (Li et al., 2020). This suggests that the Chinese population may be universally exposed to MeP. The median concentration of MeP $(3.4 \mathrm{ng} / \mathrm{mL}) \mathrm{in} \mathrm{serum}$ of the study population is higher than that reported in Guangdong $(0.21 \mathrm{ng} / \mathrm{mL})$ (Song et al., 2020), Cambridge (1.6 $\mathrm{ng} / \mathrm{mL}$ ) (Fisher et al., 2020), and Granada (1.41 ng/mL) (Iribarne-Duran et al., 2020), but is much lower than that in Tamil Nadu (13.18 ng/mL) (Shekhar et al., 2017). This is probably attributed to the differences in lifestyle and use of individual care products.

$\operatorname{PrP}$ (mean, $1.9 \mathrm{ng} / \mathrm{mL}$ ) was the secondary abundant paraben measured in human serum. Many studies have described the occurrence of PrP in human serum. For example, Yu et al. (2021) reported that PrP was detected in all samples $(n=50)$ at the geometric mean concentration of $0.31 \mathrm{ng} / \mathrm{mL}$ from Beijing, China. A biomonitoring study showed that $53 \%$ of PrP was measured in menstrual blood samples from Granada (Spain) at the mean concentration of $1.7 \mathrm{ng} / \mathrm{mL}$ (Iribarne-Duran et al., 2020). In this study, PrP was measured in $71 \%$ and $53 \%$ of serum samples in RA cases and healthy people, respectively. Previously, studies had demonstrated extremely high PrP concentration levels in personal care products, such as creams (mean $746 \mathrm{ng} / \mathrm{mL}$ ) and body or hand lotion (mean $596 \mathrm{ng} / \mathrm{mL}$ ) from China (Guo et al., 2014). As a result, the Hangzhou population may be exposed to extensive PrP through the daily use of personal care products.

EtP was detected in $52 \%$ of human serum samples with a mean concentration of $1.4 \mathrm{ng} / \mathrm{mL}$. Previous studies showed that the detection frequencies and concentrations of EtP in foodstuffs were $84 \%$ and $11 \mathrm{ng} / \mathrm{mL}$, respectively (Liao et al., 2013). Therefore, food intake may be one of the major sources of EtP exposure in Hangzhou, China. BuP was the least frequently detected paraben in human serum, with the detection frequencies lower than $55 \%$.

Interestingly, low concentrations and detection frequency of BuP had been reported in various matrixes, such as breast milk, indoor dust, river water, and soil, collected from several countries (Alshana et al., 2015, Wang et al., 2012, Zhao et al., 2020). The low detection frequency of BuP in serum maybe because of the low use of BuP in personal care products in China, and the rapid excretion of BuP in humans (due to its low hydrophobicity) (Guo et al., 2014). 
To our knowledge, this is the first report to investigate the association between environmental paraben exposure and increased immune markers for RA in a general population cohort in Hangzhou. In this cohort, the patients were reviewed by medical records for ACPA, RA, immunoglobulins, and physical examination to verify disease, and approximately $85 \%$ agreed to a medical review, with an $80 \%$ efficiency rate. Our study showed that increased MeP exposure was significantly associated with increased levels of RF and ACPA. RF and ACPA are considered to be the specific autoantibody against the IgG Fc segment (Dobloug et al., 1980, Liou and Huang, 2020, Wang et al., 2017). Therefore, we examined the correlation between MeP concentrations in serum and levels of IgG in this study. The result denoted that a unit increase in serum MeP concentration levels was correlated with increased IgG levels. Despite that, whether MeP-induced IgG increase affects RF levels remains to be further exploited.

Further, a significant association of residual concentrations of MeP in serum with the incidence of RA was found. Plausible explanations for the association between MeP and RA include the initiation or exacerbation of the inflammatory response by affecting the oxidative homeostasis in the host. A toxicology experiment studied by Pishkari et al. found that increased levels of MeP in hemoglobin substrates resulted in earlier production of glycosylation end products and significantly increased the production of reactive oxygen species (ROS) (Pishkari et al., 2020). Another study on semen reported that exposure to $13 \mathrm{mM}$ MeP for 2 hours inhibited semen cell activity while causing an increase in ROS (Samarasinghe et al., 2018). Upregulation of ROS in the host may cause damage to biomolecules (e.g., proteins and lipids) by activating different signaling pathways (Phull et al., 2018). The oxidative stress may trigger an inflammatory response through the non-enzymatic degradation of proteins following amino acid oxidation, leading to the stable production of late glycosylation end products, which would allow the production of specific proteins associated with RA (Hitchon and El-Gabalawy, 2004). In addition, the study of Pishkari et al. also reported that lipid peroxidation (LPO) is enhanced with increasing concentrations of MeP (0-100 $\mu \mathrm{M}$ ) exposure (Pishkari et al., 2020). Polyunsaturated fatty acids generate lipid peroxyl radicals under peroxidation, leading to cell membrane damage. Bereketolu and Pradhan et al. found that MeP exposure may trigger the secretion of inflammatory cytokines by inducing oxidative stress or altering fatty acid metabolism (Bereketoglu and Pradhan, 2019). In zebrafish experiments, the expression levels of two pro-inflammatory cytokines, tumor necrosis factor and interleukins, were significantly increased in the larval stage after exposure to MeP at concentrations of 1 and $10 \mu \mathrm{M}$ (Bereketoglu and Pradhan, 2019). IL-1 and TNF-a play important roles in RA by triggering multiple signaling pathways to activate transcription factors that affect relevant inflammatory mediator genes, leading to impaired host tolerance (Phull et al., 2018). Overall, these findings offer evidence for the relationship between PFOA and RA in the present study.

As for C-reactive protein, their relationships with higher serum MeP as well as PrP concentration levels were observed in the current study. Previously, the Puerto Rico Testsite for Exploring Contamination Threats study in pregnant women reported that there were significant associations between urinary BuP exposure (1.03 ng/mL), but not MeP and PrP, and levels of C-RP (Watkins et al., 2015), which was inconsistent with the results of this study. In another epidemiological study of paraben exposure to pregnant women in the US, MeP and PrP concentrations in urine were not related to C-RP levels (Aung et al., 2019). This may be explained by the change of exposure profiles and the difference between different target populations and the analysis matrix. The National Health and Nutrition Examination Survey between 2005 and 2006 years showed that the odds of aeroallergen sensitization increased with the urinary BuP exposure level (Savage et al., 2012), but in this study, we did not find a significant relationship between BuP and immune markers. Therefore, this study needs to be replicated.

This work also has some limitations. First, parabens are metabolized rapidly in the blood (at approximately 24-72 hours), which may bias the results of paraben and RA risk in this study. Therefore, the relationship between paraben

Page $11 / 16$ 
and the incidence of RA was also evaluated based on the exploration of the linear relationship between paraben and immunological indicators. Second, the limited sample size may also have influenced the results of this study. Finally, we were not aware of other potential environmental contaminants in the serum of the general population of Hangzhou, so we could not exclude confounding of paraben by exposure levels of other environmental toxicants.

\section{Conclusions}

We conducted paraben exposure measurements among 290 Chinese population and examined the connection between paraben levels in serum and immune markers for RA. MeP $(4.7 \mathrm{ng} / \mathrm{mL})$ is the most abundant detected paraben in human serum, followed by $\operatorname{PrP}(1.9 \mathrm{ng} / \mathrm{mL})$, EtP $(1.4 \mathrm{ng} / \mathrm{mL})$, and BuP $(1.09 \mathrm{ng} / \mathrm{mL})$. This study first reports that increased human serum MeP concentrations are correlated with increased RF, ACPA, and IgG levels. We also identified that MeP and PrP concentrations in human serum were also significantly associated with levels of CRP, which suggests the evidence that exposure to parabens can contribute to a higher risk of RA.

\section{Declarations}

\section{ACKNOWLEDGEMENTS}

This work was supported by the National Natural Science Foundation of China (Grant numbers: U20A20134).

\section{AUTHOR INFORMATION}

Corresponding author

Jing Xue

Phone: +86-13858121751; Fax: +86-0571-87767104; E-mail: Jingxue@zju.edu.cn.

Hangbiao Jin

Phone: +86-15088295690; Fax: +86-0571-86721068; E-mail: hangbiao@zjut.edu.cn.

\section{ETHICAL APPROVAL AND CONSENT TO PARTICIPATE}

The study procedures were approved by the Ethics Committee of the Second Affiliated Hospital of Zhejiang University School of Medicine. All subjects have signed a written informed consent form.

\section{CONSENT TO PUBLISH}

The work in this manuscript has not been previously published and is not under consideration of other journals.

\section{AUTHOR STATEMENT}

Yun Zhao: Methodology, Formal analysis, Writing- Original draft preparation. Writing-Reviewing and Editing.

Jianli Qu: Data curation, Investigation.

Meirong Zhao: Conceptualization, Methodology.

Pengfei Wu: Data curation, Investigation. 
Hangbiao Jin: Data curation. Writing- Reviewing and Editing.

\section{DECLARATION OF INTERESTS}

The authors declare that they have no known competing financial interests or personal relationships that could have appeared to influence the work reported in this paper.

The authors declare the following financial interests/personal relationships which may be considered as potential competing interests:

\section{References}

1. Adoamnei E, Mendiola J, Monino-Garcia M, Vela-Soria F, Iribarne-Duran LM, Fernandez MF, Olea N, Jorgensen N, Swan SH, Torres-Cantero AM (2018) Urinary concentrations of parabens and reproductive parameters in young men. Sci Total Environ 621:201-209

2. Aker AM, Johns L, McElrath TF, Cantonwine DE, Mukherjee B, Meeker JD (2018) Associations between maternal phenol and paraben urinary biomarkers and maternal hormones during pregnancy: A repeated measures study. Environ Int 113:341-349

3. Alshana U, Ertas N, Goger NG (2015) Determination of parabens in human milk and other food samples by capillary electrophoresis after dispersive liquid-liquid microextraction with back-extraction. Food Chem 181:1-8

4. Andersen FA (2008) Final Amended Report on the Safety Assessment of Methylparaben, Ethylparaben, Propylparaben, Isopropylparaben, Butylparaben, Isobutylparaben, and Benzylparaben as used in Cosmetic Products. Int J Toxicol 27:1-82

5. Angerer J, Ewers U, Wilhelm M (2007) Human biomonitoring: state of the art. Int J Hyg Environ Health 210(34):201-228

6. Aung MT, Ferguson KK, Cantonwine DE, Bakulski KM, Mukherjee B, Loch-Caruso R, McElrath TF, Meeker JD (2019) Associations between maternal plasma measurements of inflammatory markers and urinary levels of phenols and parabens during pregnancy: A repeated measures study. Sci Total Environ 650(Pt 1):1131-1140

7. Bereketoglu C, Pradhan A (2019) Comparative transcriptional analysis of methylparaben and propylparaben in zebrafish. Sci Total Environ 671:129-139

8. Bledzka D, Gromadzinska J, Wasowicz W (2014) Parabens. From environmental studies to human health. Environ Int 67:27-42

9. Boberg J, Taxvig C, Christiansen S, Hass U (2010) Possible endocrine disrupting effects of parabens and their metabolites. Reprod Toxicol 30(2):301-312

10. de Silva PS, Yang X, Korzenik JR, Goldman RH, Arheart KL, Caban-Martinez AJ (2017) Association of urinary phenolic compounds, inflammatory bowel disease and chronic diarrheal symptoms: Evidence from the National Health and Nutrition Examination Survey. Environ Pollut 229:621-626

11. Dobloug JH, Forre O, Kass E, Thorsby E (1980) HLA antigens and rheumatoid arthritis. Association between HLA-DRw4 positivity and IgM rheumatoid factor production. Arthritis Rheum 23(3):309-313

12. Ferreira AMC, Moder M, Laespada MEF (2011) GC-MS determination of parabens, triclosan and methyl triclosan in water by in situ derivatisation and stir-bar sorptive extraction. Anal Bioanal Chem 399(2):945-953

13. Fisher BG, Thankamony A, Mendiola J, Petry CJ, Frederiksen H, Andersson AM, Juul A, Ong KK, Dunger DB, Hughes IA, Acerini CL (2020) Maternal serum concentrations of bisphenol A and propyl paraben in early 
pregnancy are associated with male infant genital development. Hum Reprod 35(4):913-928

14. Fisher M, MacPherson S, Braun JM, Hauser R, Walker M, Feeley M, Mallick R, Berube R, Arbuckle TE (2017) Paraben Concentrations in Maternal Urine and Breast Milk and Its Association with Personal Care Product Use. Environ Sci Technol 51(7):4009-4017

15. Guo Y, Wang L, Kannan K (2014) Phthalates and parabens in personal care products from China: concentrations and human exposure. Arch Environ Contam Toxicol 66(1):113-119

16. Han J, Washington C (2005) Partition of antimicrobial additives in an intravenous emulsion and their effect on emulsion physical stability. Int J Pharm 288(2):263-271

17. Hitchon CA, El-Gabalawy HS (2004) Oxidation in rheumatoid arthritis. Arthritis Res Ther 6(6):265-278

18. Iribarne-Duran LM, Domingo-Pinar S, Peinado FM, Vela-Soria F, Jimenez-Diaz I, Barranco E, Olea N, Freire C, Artacho-Cordon F, Ocon-Hernandez O (2020) Menstrual blood concentrations of parabens and benzophenones and related factors in a sample of Spanish women: An exploratory study. Environ Res 183:109228

19. Janjua NR, Frederiksen H, Skakkebaek NE, Wulf HC, Andersson AM (2008) Urinary excretion of phthalates and paraben after repeated whole-body topical application in humans. Int J Androl 31(2):118-130

20. Jurewicz J, Radwan M, Wielgomas B, Karwacka A, Klimowska A, Kaluzny P, Radwan P, Hanke W (2020) Parameters of ovarian reserve in relation to urinary concentrations of parabens. Environ Health 19(1):26

21. Kang KS, Che JH, Ryu DY, Kim TW, Li GX, Lee YS (2002) Decreased sperm number and motile activity on the F1 offspring maternally exposed to butyl p-hydroxybenzoic acid (butyl paraben). J Vet Med Sci 64(3):227-235

22. Li A, Zhuang T, Zhu Q, Song M, Liao C, Jiang G (2020) Concentration and distribution of parabens, triclosan, and triclocarban in pregnant woman serum in China. Sci Total Environ 710:136390

23. Liao C, Chen L, Kannan K (2013) Occurrence of parabens in foodstuffs from China and its implications for human dietary exposure. Environ Int 57-58:68-74

24. Liou LB, Huang CC (2020) Reverse expression of alpha2,6-sialic acid ratios on IgG, IgM, and IgG/lgM autoantibodies correlates with mouse arthritis and rheumatoid arthritis disease activity. J Chin Med Assoc 83(12):1079-1086

25. Oishi S (2001) Effects of butylparaben on the male reproductive system in rats. Toxicol Ind Health 17(1):31-39

26. Phull AR, Nasir B, Haq IU, Kim SJ (2018) Oxidative stress, consequences and ROS mediated cellular signaling in rheumatoid arthritis. Chem Biol Interact 281:121-136

27. Samarasinghe S, Krishnan K, Naidu R, Megharaj M, Miller K, Fraser B, Aitken RJ (2018) Parabens generate reactive oxygen species in human spermatozoa. Andrology 6(4):532-541

28. Savage JH, Matsui EC, Wood RA, Keet CA (2012) Urinary levels of triclosan and parabens are associated with aeroallergen and food sensitization. J Allergy Clin Immunol 130(2):453-460e457

29. Shekhar S, Sood S, Showkat S, Lite C, Chandrasekhar A, Vairamani M, Barathi S, Santosh W (2017) Detection of phenolic endocrine disrupting chemicals (EDCs) from maternal blood plasma and amniotic fluid in Indian population. Gen Comp Endocrinol 241:100-107

30. Snodin D (2017) Regulatory risk assessments: Is there a need to reduce uncertainty and enhance robustness? Update on propylparaben in relation to its EU regulatory status. Hum Exp Toxicol 36(10):1007-1014

31. Song S, He Y, Zhang T, Zhu H, Huang X, Bai X, Zhang B, Kannan K (2020) Profiles of parabens and their metabolites in paired maternal-fetal serum, urine and amniotic fluid and their implications for placental transfer. Ecotoxicol Environ Saf 191:110235 
32. Tian Z, McLaughlin J, Verma A, Chinoy H, Heald AH (2021) The relationship between rheumatoid arthritis and diabetes mellitus: a systematic review and meta-analysis. Cardiovasc Endocrinol Metab 10(2):125-131

33. Vela-Soria F, Ballesteros O, Rodriguez I, Zafra-Gomez A, Ballesteros L, Cela R, Navalon A (2013) A new treatment by dispersive liquid-liquid microextraction for the determination of parabens in human serum samples. Anal Bioanal Chem 405(23):7259-7267

34. Vernet C, Pin I, Giorgis-Allemand L, Philippat C, Benmerad M, Quentin J, Calafat AM, Ye X, Annesi-Maesano I, Siroux V, Slama R, Group EM (2017) In Utero Exposure to Select Phenols and Phthalates and Respiratory Health in Five-Year-Old Boys: A Prospective Study. Environ Health Perspect 125(9):097006.-C.C.S.

35. Wang H, Bi X, Xu L, Li Y (2017) Negative interference by rheumatoid factor in alpha-fetoprotein chemiluminescent microparticle immunoassay. Ann Clin Biochem 54(1):55-59

36. Wang L, Liao C, Liu F, Wu Q, Guo Y, Moon HB, Nakata H, Kannan K (2012) Occurrence and human exposure of phydroxybenzoic acid esters (parabens), bisphenol A diglycidyl ether (BADGE), and their hydrolysis products in indoor dust from the United States and three East Asian countries. Environ Sci Technol 46(21):11584-11593

37. Watkins DJ, Ferguson KK, Del Toro A, Alshawabkeh LV, Cordero AN, Meeker JD (2015) Associations between urinary phenol and paraben concentrations and markers of oxidative stress and inflammation among pregnant women in Puerto Rico. Int J Hyg Environ Health 218(2):212-219

38. Wu C, Xia W, Li Y, Li J, Zhang B, Zheng T, Zhou A, Zhao H, Huo W, Hu J, Jiang M, Hu C, Liao J, Chen X, Xu B, Lu S, Cai Z, Xu S (2019) Repeated Measurements of Paraben Exposure during Pregnancy in Relation to Fetal and Early Childhood Growth. Environ Sci Technol 53(1):422-433

39. Yarwood A, Huizinga TWJ, Worthington J (2016) The genetics of rheumatoid arthritis: risk and protection in different stages of the evolution of RA. Rheumatology 55(2):199-209

40. Yu L, Peng F, Yuan D, Zhang L, Guo Y, Chang B, Shi X, Ding C, Liang X (2021) Correlation study of parabens in urine, serum, and seminal plasma of adult men in Beijing, China. Environ Sci Pollut Res Int

41. Zeng P, Bengtsson C, Klareskog L, Alfredsson L (2017) Working in cold environment and risk of developing rheumatoid arthritis: results from the Swedish EIRA case-control study.RMD Open3(2), e000488

42. Zhang H, Quan Q, Li X, Sun W, Zhu K, Wang X, Sun X, Zhan M, Xu W, Lu L, Fan J, Gao Y (2020) Occurrence of parabens and their metabolites in the paired urine and blood samples from Chinese university students: Implications on human exposure. Environ Res 183:109288

43. Zhao H, Zheng Y, Zhu L, Xiang L, Zhou Y, Li J, Fang J, Xu S, Xia W, Cai Z (2020) Paraben Exposure Related To Purine Metabolism and Other Pathways Revealed by Mass Spectrometry-Based Metabolomics. Environ Sci Technol 54(6):3447-3454

44. Zhao Y, Liu Y, Chen Y, Wu X, Xiao Q, Li C, Li M, Hu W, Gu H, Lu S (2021) Exposure to parabens and associations with oxidative stress in adults from South China. Sci Total Environ 774:144917-144917

45. Zhu Q, Wang M, Jia J, Hu Y, Wang X, Liao C, Jiang G (2020) Occurrence, Distribution, and Human Exposure of Several Endocrine-Disrupting Chemicals in Indoor Dust: A Nationwide Study. Environ Sci Technol 54(18):1133311343

\section{Figures}




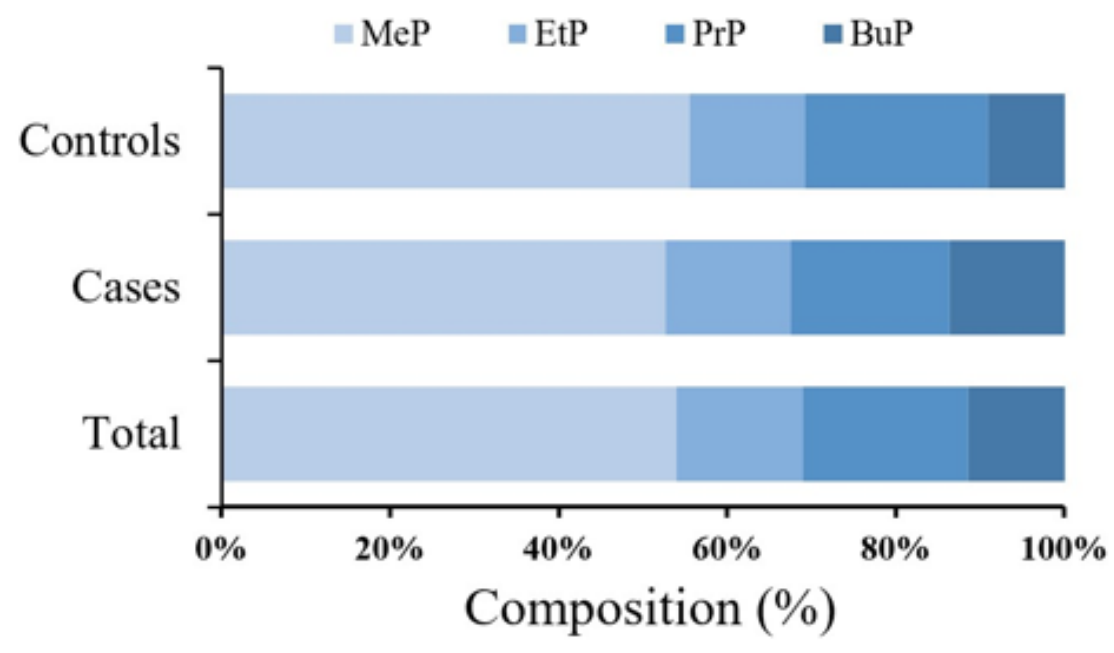

Figure 1

Composition profiles of parabens in human serum $(n=290)$ between the RA cases and controls.

\section{Supplementary Files}

This is a list of supplementary files associated with this preprint. Click to download.

- TOC.png

- highlights.docx

- parabenSI.docx 